\title{
Enhancing Sight-Word Fluency of Second-Language Elementary Students through Reading Racetracks
}

\author{
Matthias Grünke, Anne Barwasser \\ University of Cologne, Germany
}

\begin{abstract}
The purpose of this single-case analysis was to determine the effects of a reading racetrack intervention on the sight-word fluency of five struggling third and fourth graders. All participants were enrolled in a German elementary school but grew up speaking a different tongue. A multiple baseline design across subjects was applied. During the course of the intervention, four out of five children showed significant improvements in their ability to quickly recognize common German sight words. The increase in performance of one student was a little less distinct than in the cases of the other four but still remarkable. Limitations of this study and the practical implications of employing reading racetracks are discussed.
\end{abstract}

\section{Introduction}

One of the most universal school-acquired skills that influence overall success far beyond the scope of academic education is reading [1]. Advantages of a skilled reader include cognitive benefits [2], high levels of proficiency [3], higher incomes in the future [4], and a reduction in certain stress levels [5]. Conversely, struggling students whose performance is below average grapple with various problems both within and beyond academic institutions [6]. To acquire the literacy skills necessary for understanding text, an adequate reading fluency is a fundamental requirement for its function as a bridge between recognition and comprehension [7]. When reading aloud, according to the dual route theory [8], there are two accesses bridging a connection between texts and cognitive memory: the lexical route (storage of sight words) and the non-lexical route (connecting letters and sounds). Academically challenged students face problems with the lexical route caused by their limited access to the mental lexicon where words are retrieved. Word recognition is essential when it comes to reading mastery [9]. Thus, the reason for slow word recognition mainly derives from a lack of adequate stored sight words. They are included in the critical elements that determine the extent of reading comprehension development [10]. Fluent readers automatize word forms and activate their mental lexicon, whereas struggling readers experience a slowed activation of this storage when word decoding
[11]. This leads to less reading and, subsequently, inadequate development of basic decoding skills. Possessing a comprehensive range of stored known vocabulary relieves the working memory, enabling it to take a leading role in reading [12]. The working memory is composed of a limited-capacity attentional control system. Thus, if one spends too much attention on lower-level processing (e.g., word decoding), less resources will be available for higher-level comprehension of content [13]. Comparing L1 (first language) and L2 (second language) readers with each other, studies show that L1 students read at about twice the speed of L2 students [14]. The former have more sight words stored in their mental lexicon [15].

Currently, there is an unfortunate unprecedented number of struggling children and adolescents. The OECD has revealed that $16 \%$ of German students perform under the OECD average, and those with migration backgrounds, whose second language is German, demonstrate an even lower reading proficiency than non-migrant ones [16].

According to the National Assessment of Educational Progress, the academic results of only $35 \%$ of fourth graders show sufficient performance in reading [17]. Additionally, there is a risk of students left unaccounted for whose reading deficits continue to remain unaddressed after elementary school. Therefore, trying to compensate these deficits at an early stage is extremely important.

Acknowledging that fluency and sight-word acquisition play a leading role in achieving reading proficiency, while being aware of struggling students (especially second-language learners) who need to be motivated and supported, expanded research on how to remedy deficits in sight-word acquisition is indispensable. One expedient and promising approach to support second-language learners and other students who might be at risk of falling behind in school is the use of educational games. Adding playful features to an intervention has several benefits, especially in a second-language context. Various studies have demonstrated that educational games can be helpful in lifting the drudgery of otherwise dull learning situations and can be effective in increasing academic success for students at risk of failure [18], [19]. A method that has already been shown to be effective concerning this area is called reading racetracks. These are board games using drill and practice to improve sight-word fluency [20], [21], 
[22]. They consist of cells on which flashcards with unknown words are placed upside down (see Figure 1).

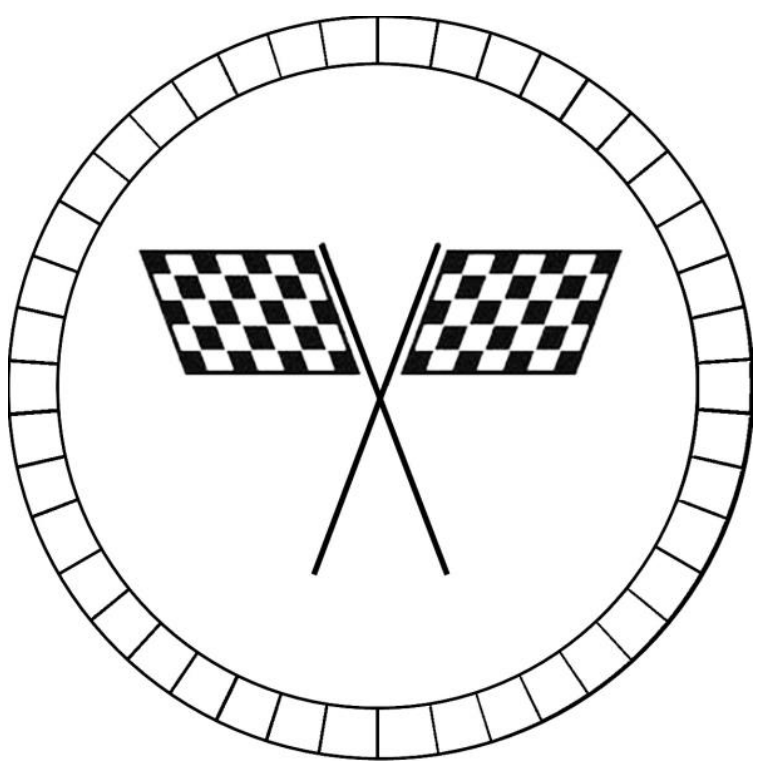

Figure 1. A simple racetrack board game

The benefits of reading racetracks have been tested a number of times [20], [21], [22], [23], [24], [25], [26], [27], [28], [29]. However, never before have the effects been evaluated for second-language learners. The purpose of the present study was to elicit whether this procedure can also be an effective literacy tool for these kinds of students. We focused on struggling elementary school readers who lived in Germany but were born someplace else and spoke a different tongue at home.

\section{Methods}

The participants of this study were five students from an inclusive elementary school in an urban area of Northrhine-Westfalia (Germany). We conducted the One-Minute-Reading-Subtest from the Salzburg Reading- und Writing-Test (SLRT II) [30] with 20 students in grades 3 and 4 who were considered weak readers by their classroom teachers. In order to be included in the study, children had to score in the last percentile. However, they had to be familiar with all the letters of the alphabet and be capable of blending them. Additionally, German had to be their second language, and the lingua franca at home had to be foreign. Five students qualified for inclusion in the experiment: Alia, Bjorgvin, Catinca, Daniela, and Edita (names changed for anonymity). Nonverbal intelligence scores were available for all participants in their school records. Accordingly, every child in this research demonstrated average intellectual abilities.
Alia (female) was 9 years at the time of the study and attended third grade. Her family fled to Germany from Syria about three years before this investigation was conducted. She spoke, read, and wrote Arabic fluently but experienced severe problems reading German. The family of Bjorgvin (male) moved from Nigeria to Germany when he was a toddler. Everyone in his home spoke English as the primary means of communication. Bjorgvin also attended third grade. Catinca (female) was already 11 years old when she participated in this experiment and was attending fourth grade. She was born in Rumania and moved to Germany at the age of three. At the time of her enrollment in elementary school, she spoke only Rumanian. Daniela (female) was 8 years old, attended third grade, and was originally from Italy. She moved to Germany a couple of months before she had to start elementary school and spoke only Italian until then. The last participant was 8-year-old Edita (female), who was born in Bulgaria and attended third grade. Her family communicated exclusively in Bulgarian at home.

For the intervention, we prepared a reading racetrack similar to the one in Figure 1 that contained 40 fields. The cards that were placed upside down on the fields each had a simple word printed on them that we took from the One-Minute-Reading-Subtest of the SLRT II. We employed a multiple baseline across subjects design (AB) [31] with staggered start times. The baseline was conducted across three days for Alia, four days for Bjorgvin, five days for Catinca, six days for Daniela, and seven days for Edita. To increase the internal validity of the experiment, the allocation of the students to the different start times was determined by chance. Before the intervention commenced, the five participants were individually taken to a resource room within the school. A female graduate college student, who served as interventionist, played a card game with the participants for 15 minutes and then asked the children to read from one of randomly arranged lists with the 40 words from the One-Minute-ReadingSubtest. She tracked the time and prompted them to stop after exactly 1 minute. During the treatment, the interventionist played the racetrack game with each student individually for a quarter of an hour. Here, the children rolled a die, moved the number of fields forward, picked up the respective card, and read the word out loud. In case a participant made a mistake, the graduate student corrected her or him. Just as during baseline conditions, the interventionist measured the students' performance after the 15 minutes were over.

The number of correctly read words per minute functioned as the dependent variable and was recorded each day by the interventionist. While performance was measured as just described, no corrections were given. Erroneously read words were not counted. 


\section{Results}

Table 1 displays some descriptive data for the five children. As can be seen, Catinca, Daniela, and Edita all missed one measurement in the baseline due to illness.

On average, three out of the five participants read less than five words per minute correctly prior to the treatment. They increased their mean score by at least $150 \%$ during the intervention. Bjorgvin started out with an average value of 6.25 and was able to boost his performance by $124 \%$. Edita had a relatively high score of 9.33 to begin with. Her achievement increased only by about $60 \%$.

Figure 2 depicts the number of words read correctly within a minute by the five children.

The baselines can be considered fairly stable. All but one participant demonstrated a gradual gain in performance. Only Edita seemed to stay at a comparably constant level during the intervention. The students did not show an immediate increase in achievement but improved successively.

Table 1. Descriptive data for the five participants

\begin{tabular}{lccccc}
\hline & Alia & Bjorgvin & Catinca & Daniela & Edita \\
\hline N probes A & 3 & 4 & 5 & 6 & 7 \\
\hline N probes B & 9 & 8 & 7 & 6 & 5 \\
\hline Missing probes A & 0 & 0 & 1 & 1 & 1 \\
\hline Missing probes B & 0 & 0 & 0 & 0 & 0 \\
\hline Mean A & 4.67 & 6.25 & 4.25 & 4.40 & 9.33 \\
\hline Mean B & 13.00 & 14.00 & 10.86 & 11.00 & 15.20 \\
\hline Mean increase & $178.37 \%$ & $124.00 \%$ & $155.53 \%$ & $150.00 \%$ & $62.92 \%$ \\
\hline SD A & 1.53 & 2.50 & 0.50 & 1.34 & 2.34 \\
\hline SD B & 5.55 & 4.63 & 3.34 & 2.61 & 1.79 \\
\hline Minimum A & 3 & 3 & 4 & 3 & 6 \\
\hline Minimum B & 5 & 8 & 7 & 9 & 13 \\
\hline Maximum A & 6 & 9 & 5 & 16 & 12 \\
\hline Maximum B & 19 & 21 & 16 & & 17 \\
\hline
\end{tabular}
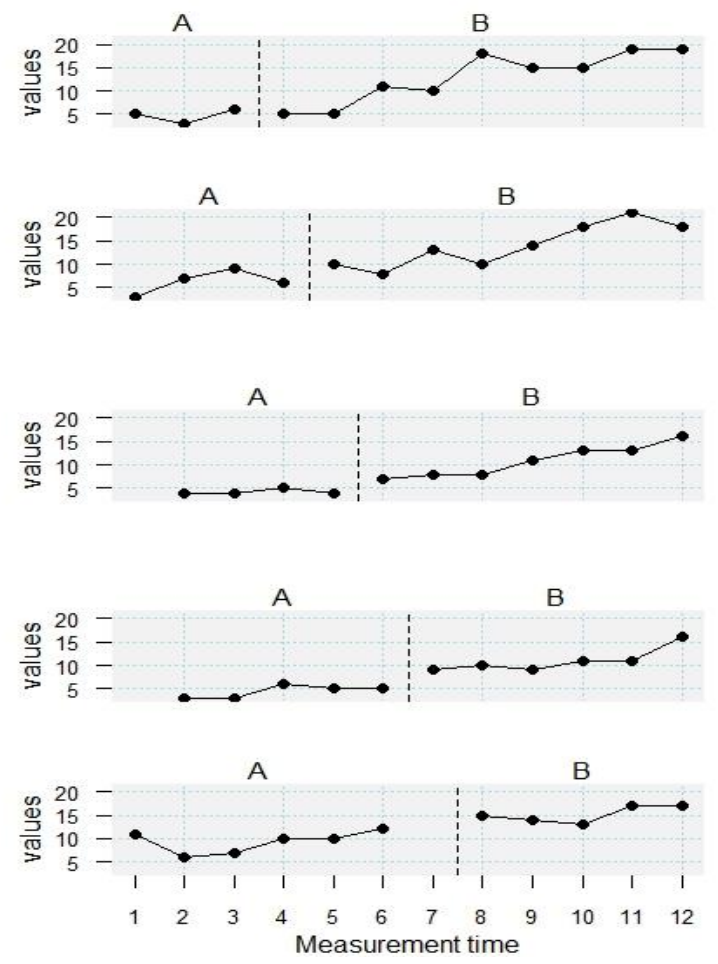

Figure 2. Number of correctly read words per minute during phases A and B by Alia, Bjorgvin, Catinca, Daniela, and Edita 
The percentage of non-overlapping data (PND) [32] reached a perfect score of 100 in the case of Catinca, Daniela, and Edita. Alia's index was 77.78, and Bjorgvin's was 87.50. PND is the most frequently used effect size for quantifying treatment benefits in single-case studies. It is calculated by counting the number of treatment data points that exceed the highest baseline data point and then dividing this figure by the total number of data points in the treatment phase. The improvement rate difference (IRD) [33] reached 1.00 in the case of Alia, 0.89 in the case of Bjorgvin, 1.00 in the case of Catinca, 1.00 in the case of Daniela, and 1.00 in the case of Edita. IRD is often considered an improvement over the PND. It is defined as the number of improved baseline measurements that is subtracted from the number of improved treatment phase measurements. All PND and IRD scores in this research are evidence for formidable to very high treatment gains.

Weighted Tau-U scores (A vs. B + trend B - trend A) were calculated to supplement previous analyses using a specific online tool [34]. This index accounts for non-overlap of data points between intervention phases, for data trend within the intervention phase, and for data trend within the baseline phase [35]. Values can vary from -1 to 1 . A positive score indicates an improvement in performance. The average overall Tau-U value for the five participants was 0.62 ( $p<.01)$. Scores from .60 to 0.80 represent a large effect [36]. Thus, we can conclude that our group of five children benefited from the intervention in a notable way.

Looking at the five participants individually, we can state that Alia achieved a weighted Tau-U index of $0.71(\mathrm{z}=3.27 ; \mathrm{p}=<.001)$, Bjorgvin one of $0.73(\mathrm{z}$ $=3.31 ; \mathrm{p}<.001)$, Catinca one of $0.70(\mathrm{z}=3.20 ; \mathrm{p}<$ $.001)$, Daniela one of $0.56(\mathrm{z}=2.56 ; \mathrm{p}<.01)$, and Edita one of $0.41(\mathrm{z}=1.86 ; \mathrm{p}=.06)$. Thus, except for Edita, all students achieved statistically significant improvements.

\section{Discussion}

The data collected during our experiment indicates that playing the racetrack game was very beneficial in building sight-word fluency in our participants. Before the intervention, they were able to only read between three and six simple words per minute. However, as soon as the treatment was carried out, their performance gradually increased. The mean enhancements varied between $62.92 \%$ and $178.37 \%$. All effect size calculations (PND, IRD, and Tau-U) speak to the high potency of the approach. What is interesting to note is the fact that the student who started out with the highest scores (Edita) profited the least from the treatment. She was the only one whose Tau-U values failed to hit the statistical significance benchmark. In fact, the correlation (Spearman) between the mean scores in phase $\mathrm{A}$ and the percentage increase from phase A to B equaled -.70. This finding is not surprising. The phenomenon that low-achieving students demonstrate greater gains during the course of an intervention than highachieving ones has been reported many times and is sometimes referred to as the Robin Hood effect in education [41]. However, the overall findings of this single-case analysis correspond with previous research on the topic and provide evidence for the assumption that reading racetracks can not only be successfully implemented with weak readers in general but also specifically with foreign-language learners.

There are several limitations to be considered when interpreting the findings of this experiment. First, this research employed only five participants from a particular age bracket. Therefore, generalization is limited. What is more, we focused on second-language learners in general, not on students from a particular language background. We involved native Arabic, English, Rumanian, Italian, and Bulgarian speakers. The intervention worked well with the participants. Yet, we must be cautious with drawing conclusions about the effectiveness of the training with children who were raised with other languages than the ones mentioned. Besides, this study was conducted in Germany and aimed at teaching elementary school children German sight words. More research is warranted in the area of testing the benefits of reading racetracks with secondlanguage learners acquiring another tongue than German.

A further limitation pertains to the lack of followup data. We have no way of knowing how stable the treatment effects were over time. In addition, we neglected to collect data on treatment fidelity and social validity. Future studies should acquire information on long-term effects, the practicality of the procedures and findings, and the extent to which the intervention is delivered as intended. The quality of research would reach an even higher level if these features were considered. However, time constraints and limited resources available precluded the collection of these data.

Despite its shortcomings, this study provides important evidence for the value of reading racetracks in teaching second-language learners with severe deficits in recognizing basic sight words. Teachers long for easy-to-implement approaches that elicit improvements in fundamental academic skills. Having to meet the needs of a very diverse student body is becoming ever more challenging. Especially in parts of the world like urban regions of Germany with usually very high percentages of children and adolescents with an immigrant background, it is very challenging to do justice to every learner. Far too many students who receive instruction in a language they did not grow up with fall through the cracks, leaving school without graduating. This study gives 
rise to the hope that simple techniques like reading racetracks can help to close the gap for struggling second-language learners between underdeveloped skill levels and respective curriculum standards.

Future research could focus on implementing reading racetracks in a peer-tutorial setting on a class-wide basis. The technique seems simple enough for children and adolescents to create and correct their own racetracks. It is cost effective, requires virtually no training to implement, and could certainly help teachers tackle the challenge of providing ways and means to individually support students who are part of very diverse groups of learners.

\section{References}

[1] Lent, C.R., \& Voight, M.M. (2018). Disciplinary literacy in action: How to create and sustain school-wide culture of deep reading, writing, and thinking. Thousand Oaks, CA: Corwin.

[2] Cunningham, A.E., \& Stanovich, K. (2003). Reading can make you smarter! Principal, 83, 34-39.

[3] Allington, R. (2012). What really matters for struggling readers. New York, NY: Pearson.

[4] Chiswick, B.R., Lee, Y.L., \& Miller, P.W. (2003). Schooling, literacy, numeracy, and labor market success, The Economic Record, 70, 165-181.

[5] Rizzolo, D., Zipp, G.P., Stiskal, D., \& Simpkins, S. (2009). Stress management strategies for students: The immediate effects of Yoga, humor and reading on stress. Journal of College Teaching \& Reading, 6, 79-88.

[6] National Reading Panel (2000). Teaching children to read. Washington, DC: National Institute of Child Health and Human Development.

[7] National Institute for Literacy (2009). Developing early literacy: Report of the National Early Literacy Panel. Louisville, KY: National Center for Family Literacy.

[8] M. Coltheart, M., Curtis, B., Atkins, P., \& Haller, M. (1993). Models of reading aloud: Dual-route and paralleldistributed-processing approaches. Psychological Review, 100, 589-608.

[9] Compton, D.L. (1997). Using a developmental model to access children's word recognition. Intervention in School and Clinic, 32, 283-294.

[10] Roembke, T.C., Hazeltine, E., Reed, D.K., \& McMurray, B. (2019). Automaticity of word recognition is a unique predictor of reading fluency in middle-school students. Journal of Educational Psychology, 111, 314-330.

[11] Bar-Kochva, I., \& Hasselhorn, M. (2015). In search of methods enhancing fluency in reading. Journal of Experimental Child Psychology, 140, 140-157.

[12] Grabe, W. (2004). Research on teaching reading. Annual Review of Applied Linguistics, 24, 44-69.
[13] LaBerge, D., \& Samuels, S.J. (1974). Toward a theory of automatic information processing in reading. Cognitive Psychology, 6, 293-323.

[14] Kang, H. (2014). Understanding online reading through the eyes of first and second language readers. Computers \& Education, 73, 1-8.

[15] Fraser, C.A. (2007). Reading rate in L1 mandarin and L2 English across five reading tasks. The Modern Language Journal, 91, 372-394.

[16] OECD (2016). Programme for International Student Assessment (PISA): Results from PISA 2015, Paris, France: Organisation for Economic Co-operation and Development.

[17] National Center for Education Statistics (2013). DATA POINT: Trends in CTE course-taking. Washington, DC: National Center for Education Statistics.

[18] Gruss, J. (2016). Games as a tool for teaching English vocabulary to young learners. World Scientific News, 53, 67-109.

[19] Taheri, M. (2014). The effect of using language games on vocabulary retention of Iranian elementary EFL learners. Journal of Language Teaching and Research, 5, 544-549.

[20] Erbey, R., McLaughlin, T.F., Derby, K.M., \& Everson, M. (2011). The effects of using flashcards with reading racetrack to teach letter sounds, sight words, and math facts to elementary students with learning disabilities. International Electronic Journal of Elementary Education, 3, 213-226.

[21] Falk, M., Band, M., \& McLaughlin, T.F. (2003). The effects of reading racetracks and flash-cards on sight word vocabulary of three third grade students with a specific learning disability. International Journal of Special Education, 18, 51-57.

[22] Hyde, C.A., McLaughlin, T.F., \& Everson, M. (2009). The effects of reading racetracks on sight word fluency and acquisition for two elementary students with disabilities. The Open Social Science Journal, 2, 1-4.

[23] Alexander, C.T., McLaughlin, T.F., \& Derby, K.M. (2008). The effects of reading racetracks on sight words across four elementary students with differing disabilities. The Open Rehabilitation Journal, 1, 47-52.

[24] Crowley, K., McLaughlin, T.F., \& Kahn, R. (2013). The effects of direct instruction flashcards, reading racetracks on sight word skills for two students with autism. Journal of Developmental and Physical Disabilities, 25, 297-311.

[25] Green, C., McLaughlin, T.F., Derby, K.M., \& Lee, K. (2010). Using reading racetracks and flashcards to teach sight words to students with disabilities. Journal of Educational Research, 13, 84-98.

[26] Hopewell, K., McLaughlin, T.F., \& Derby, K.M. (2011). The effects of reading racetracks with direct instruction flashcards and a token system on sight word 
acquisition for two primary students with severe conduct disorders. Electronic Journal of Research in Educational Psychology, 9, 693-710.

[27] Kaufman, L., McLaughlin, T.F., Derby, K.M., \& Waco, T. (2011). Employing reading racetracks and DI flashcards with and without cover, copy, and compare and rewards to teach of sight words to three students with learning disabilities in reading. Educational Research Quarterly, 34, 24-44.

[28] McGrath, G.L., McLaughlin, T. F., Derby, K.M., \& Bucknell, W. (2012). The effects of using reading racetracks for teaching of sight words to three third-grade students with learning disorders. Educational Research Quarterly, 35, $50-66$.

[29] Rinaldi, L., Sells, D., \& McLaughlin, T.F. (1997). The effects of reading racetracks on the sight word acquisition and fluency of elementary students. Journal of Behavioral Education, 7, 219-233.

[30] Moll, K., \& Landerl, K. (2014). Salzburg reading and spelling test. Göttingen, Germany: Hogrefe.

[31[ Ledford, J.R., \& Gast, D.L. (2018). Single case research methodology. New York, NY: Routledge.

[32] Scruggs, T.E., Mastropieri, M.A., \& Casto, G. (1987). The quantitative synthesis of single subject research: Methodology and validation. Remedial and Special Education, 8, 24-33.

[33] Parker, R.I., Vannest, K.J., \& L. Brown, L. (2009). The improvement rate difference for single case research. Exceptional Children, 75, 135-150.

[34] Vannest, K.J., Parker, R.I., \& Gonen, O. (2019) Single case research: Web based calculators for SCR analysis [Web-based application], College Station, TX, Texas A\&M University, Retrieved from www.singlecaseresearch.org.

[35] Parker, R.I., Vannest, K.J., Davis, J.L., \& Sauber, S.B. (2011). Combining non-overlap and trend for single-case research: Tau-U. Behavior Therapy, 42, 284-299.

[36] Vannest, K.J., \& Ninci, J. (2015). Evaluating intervention effects in single-case research designs. Journal of Counseling \& Development, 93, 403-411.

[37] Häfner, I., Flunger, B., Dicke, A.-L., Gaspard, H., Brisson, B.M., Nagengast, B., \& Trautwein, U. (2017). Robin Hood Effects on motivation in math. Developmental Psychology, 53, 1522-1539. 